Wilfrid Laurier University

Scholars Commons @ Laurier

2008

\title{
Cigarette Smoke Suppresses Type I Interferon-Mediated Antiviral Immunity in Lung Fibroblast and Epithelial Cells
}

\author{
Carla M.T. Bauer \\ McMaster University \\ Stephanie J. DeWitte-Orr \\ Wilfrid Laurier University, sdewitteorr@wlu.ca \\ Kyle R. Hornby \\ McMaster University \\ Caleb C.J. Zavitz \\ McMaster University \\ Brian D. Lichty \\ McMaster University
}

See next page for additional authors

Follow this and additional works at: https://scholars.wlu.ca/biol_faculty

\section{Recommended Citation}

Bauer, Carla M.T.; DeWitte-Orr, Stephanie J.; Hornby, Kyle R.; Zavitz, Caleb C.J.; Lichty, Brian D.; Stämpfli, Martin R.; and Mossman, Karen L., "Cigarette Smoke Suppresses Type I Interferon-Mediated Antiviral Immunity in Lung Fibroblast and Epithelial Cells" (2008). Biology Faculty Publications. 15.

https://scholars.wlu.ca/biol_faculty/15

This Article is brought to you for free and open access by the Biology at Scholars Commons @ Laurier. It has been accepted for inclusion in Biology Faculty Publications by an authorized administrator of Scholars Commons @ Laurier. For more information, please contact scholarscommons@wlu.ca. 


\section{Authors}

Carla M.T. Bauer, Stephanie J. DeWitte-Orr, Kyle R. Hornby, Caleb C.J. Zavitz, Brian D. Lichty, Martin R. Stämpfli, and Karen L. Mossman 


\title{
Cigarette Smoke Suppresses Type I Interferon-Mediated Antiviral Immunity in Lung Fibroblast and Epithelial Cells
}

\author{
CARLA M.T. BAUER,,${ }^{1}$ STEPHANIE J. DEWITTE-ORR, ${ }^{1}$ KYLE R. HORNBY,${ }^{1}$ CALEB C.J. ZAVITZ, ${ }^{1}$ \\ BRIAN D. LICHTY, ${ }^{1}$ MARTIN R. STÄMPFLI, ${ }^{1,2, *}$ and KAREN L. MOSSMAN ${ }^{1,3, *}$
}

\begin{abstract}
The objective of this study was to investigate the impact of cigarette smoke on innate antiviral defense mechanisms; specifically, we examined the effects of cigarette smoke on the induction of type I interferon (IFN). We observed a dose-dependent decrease in the ability of human lung fibroblast and epithelial cells to elicit an antiviral response against a viral double-strand RNA (dsRNA) mimic, polyI:C, in the presence of cigarette smoke-conditioned medium (SCM). Mechanistically, SCM decreases the expression of IFN-stimulated gene 15 (ISG15) and IFN regulatory factor-7 (IRF-7) transcripts and suppresses the nuclear translocation of key transcription factors, nuclear factor- $\kappa \mathrm{B}(\mathrm{NF}-\kappa \mathrm{B})$ and IRF-3, after polyI:C stimulation. Furthermore, we provide evidence that the intercellular defense strategy against viral infection is also impaired. We observed a decrease in the ability of fibroblasts to elicit an antiviral state in response to IFN- $\beta$ stimulation. This was associated with decreased nuclear translocation of phosphorylated Stat1 in response to IFN- $\beta$ treatment. The effects elicited by SCM are reversible and are almost entirely abrogated in the presence of an antioxidant, such as glutathione. Our findings suggest that cigarette smoke affects the immediate-early, inductive, and amplification phases of the type I IFN response.
\end{abstract}

\section{INTRODUCTION}

A COMPLEX AND MULTILAYERED DEFENSE system protects the lungs against potentially harmful environmental agents through a combination of physical barriers and innate and adaptive immune mechanisms (Reynolds 2002; Tamura and Kurata 2004; Toews 1994). Multiple cellular signaling pathways protect the host from viral infection (Ishii and Akira 2005; Jefferies and Fitzgerald 2005). At least two innate immune pattern recognition receptors are responsible for sensing the production and accumulation of viral nucleic acids in nonimmune cells, such as fibroblasts and epithelial cells. Among these, toll-like receptors (TLRs) play an integral role in the recognition of pattern-associated molecular patterns and the subsequent activation of their respective signaling pathways. Of the four mammalian TLRs responsible for the identification of nucleic acids, TLR3 recognizes dsRNA, an intermediate in the replication of most, if not all, viruses (Alexopoulou and others 2001). Alternatively, cytoplasmic RNA helicases, such as retinoic acid-inducible gene I (RIG-I), have also been shown to bind dsRNA (Yoneyama and others 2004).
During viral infection, stimulation of TLR-3 and RIG-I activates two cellular kinases, TANK-binding kinase-1 (TBK-1) and IkappaB kinase (IKK)- $\varepsilon$, leading to interferon (IFN) regulatory factor-3 (IRF-3) phosphorylation, homodimerization, and translocation into the nucleus, where it associates with other transcription factors, such as nuclear factor $-\kappa \mathrm{B}(\mathrm{NF}-\kappa \mathrm{B})$, to form a complex that binds to the IFN-stimulated response element (ISRE) in the IFN- $\beta$ promoter (Alexopoulou and others 2001; Fitzgerald and others 2003; Servant and others 2003; Sharma and others 2003; Wathelet and others 1998; Yoneyama and others 1998). IRF-3 is also able to directly bind to several DNA-binding motifs, including the ISRE, causing the direct induction of IFN-stimulated genes (ISGs) in the absence of IFN production (Guo and others 2000; Mossman and others 2001).

The current model of the IFN-mediated antiviral response in nonimmune cells is proposed to occur in a trimodal fashion (Yoneyama and others 1998; Juang and others 1998; Sato and others 2000; Stojdl and others 2003). In the immediate-early phase, IFN- $\beta$ is produced at low levels following the activation of constitutively expressed transcription factors, such as IRF-3 and $\mathrm{NF}-\kappa \mathrm{B}$, as outlined above. During the inductive phase, se-

\footnotetext{
${ }^{1}$ The Centre for Gene Therapeutics, Department of Pathology and Molecular Medicine, ${ }^{2}$ Department of Medicine, and ${ }^{3}$ Department of Biochemistry and Biomedical Sciences, McMaster University, Hamilton, Ontario, Canada L8N $3 Z 5$.

*These authors contributed equally to this work.
} 
creted IFN- $\beta$ binds to its cellular receptor and through JakStat/IRF-9 signaling elicits the induction of several ISGs, including IRF-7. In the amplification phase, virus-activated IRF3 and IRF-7 cooperate to induce the full array of type I IFN genes, leading to enhanced ISG induction. Experimentally, polyinosine-polycytidylic acid (polyI:C), a mimic of viral dsRNA, has been shown to elicit activation of IRF-3 and NF$\kappa \mathrm{B}$, thus serving as a general inducer of this cellular innate immune response (Alexopoulou and others 2001).

Stimulation of epithelial cells and fibroblasts with polyI:C induces an antiviral state via two mechanisms: direct induction of ISGs in an IFN-independent fashion (Fig. 1A) (Wathelet and others 1992) and indirect induction of ISGs via type I IFN (Fig. 1B) (Daley and Reich 1993; Panet 1983). We and others have shown that a small subset of ISGs sufficient to induce a complete antiviral state can be induced in response to dsRNA and virus in an IRF-3-dependent, IFN-independent fashion (Wathelet and others 1998; Yoneyama and others 1998; Collins and others 2004; Lin and others 1998; Noyce and others 2006; Weaver and others 1998; Paladino and others 2006). When such an intracellular antiviral response is elicited, there is a lack of cytokine secretion and infiltration of immune cells and, therefore, minimal tissue damage. In a recently published model, we proposed that if a stimulation threshold is surpassed (Fig. 1B), both IRF-3 and NF- $\kappa$ B become activated, leading to an intercellular defense strategy that causes the production and secretion of type IIFN and proinflammatory cytokines (Paladino and others 2006).

Although in vitro experiments from the 1980s suggested that type I IFN-mediated innate antiviral immune responses are impaired on exposure to cigarette smoke (Barnes and others 1981; Sonnenfeld and Hudgens 1986), the mechanisms of IFN induction (and, hence, inhibition) were poorly understood. Since that time, significant advances in elucidating IFN signal transduction pathways have been made; therefore, assessing mechanistically how cigarette smoke influences antiviral immunity has become feasible. Here, we show that cigarette smoke suppresses not only the immediate-early phase but also the inductive phase of the type I IFN response in a dose-dependent fashion, compromising the induction of an antiviral state and

A Minimal dose of dsRNA

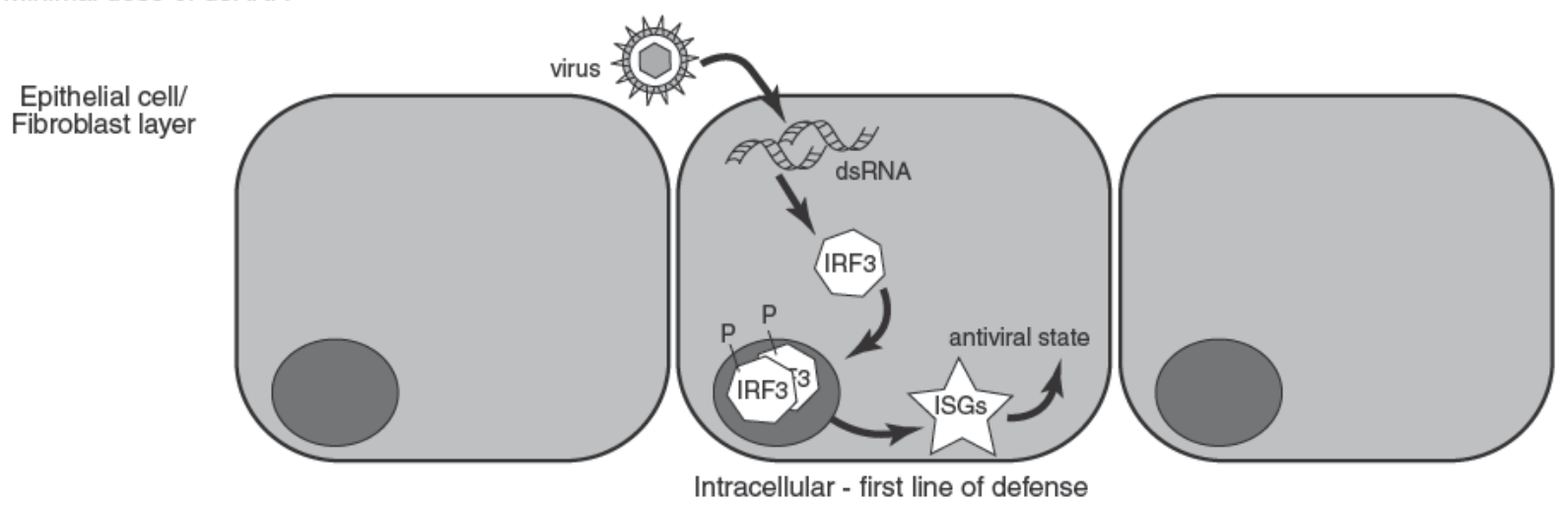

B High dose of dsRNA

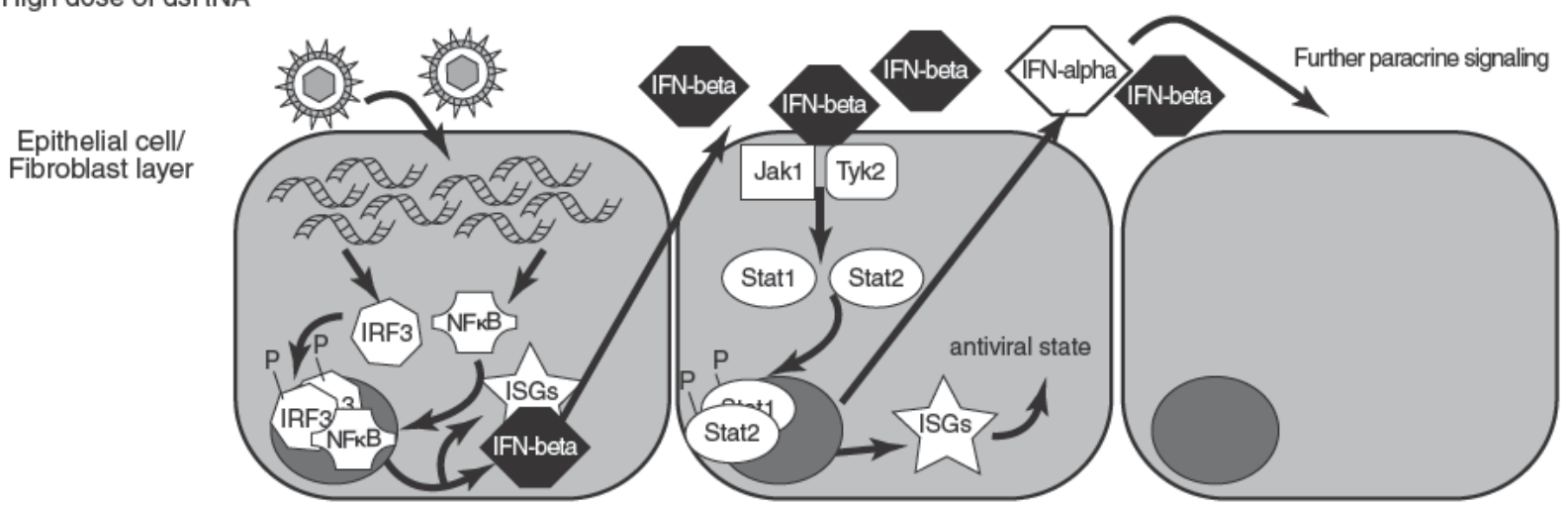

Intercellular - second line of defense

FIG. 1. Model depicting the intracellular and intercellular levels of innate antiviral defense following exposure of epithelial cells and fibroblasts to different amounts of dsRNA. (A) During low multiplicity viral infection, minimal amounts of dsRNA are produced as a by-product of viral replication. In response to dsRNA, epithelial cells and fibroblasts induce an antiviral state through the activation of IRF-3 and subsequent production of key ISGs. (B) Upon exposure of epithelial cells and fibroblasts to a high dose of dsRNA, an amount that breaches the first line of intracellular defense, activation of IRF-3 and NF- $\kappa$ B causes production of IFN- $\beta$. Paracrine secretion of IFN- $\beta$ subsequently causes activation of the Jak-Stat signaling pathway, leading to nuclear translocation of phosphorylated Stats. This causes production of IFN- $\alpha$ and further paracrine signaling of IFN- $\alpha$ and IFN$\beta$ species, leading to the production of an antiviral state in nearby cells. 
suppressing production of IFNs and several ISGs. Given the importance of type I IFN in establishing effective innate and adaptive antiviral immunity, our data have important implications for understanding the precise antiviral molecular mechanisms altered by cigarette smoke, which may contribute to the clinical manifestation of viral infections in smokers.

\section{MATERIALS AND METHODS}

\section{Reagents}

The dsRNA mimetic polyI:C (GE Healthcare, Piscataway, $\mathrm{NJ}$ ) was reconstituted in phosphate-buffered saline (PBS) at a concentration of $5 \mathrm{mg} / \mathrm{mL}$. Human tumor necrosis factor- $\alpha$ (TNF- $\alpha$ ) was harvested from supernatants of Vero cells infected with an adenoviral construct expressing human TNF- $\alpha$ (Ad $\Delta \mathrm{E} 1 . \mathrm{E} 3 \mathrm{HuTNF}-\alpha$ ) (Marr and others 1998), and dose-response assays were performed to delineate the optimal amount of supernatant required (data not shown).

\section{Generation of HuIFN- $\beta$}

The human IFN- $\beta$ gene was amplified from human fibroblasts by use of primers 5'-CAGAATTCGTTGTCAACATGACCAACAA-3' (sense) and 5'-TGCTCGAGGTTTCGGAGGTAACCTGTAA-3' (antisense). The resulting PCR product was cut with EcoRI/XhoI, cloned into pT7Blue 3 and subcloned into pMT/V5-HisA (Invitrogen, Carlsbad, CA). S2 Drosophila melanogaster cells grown in Schneider's Drosophila medium (Invitrogen) were cotransfected with $\mathrm{pMT} / \mathrm{HuIFN} \beta / \mathrm{V} 5$-His or pMT/EGFP/V5-His and pCO-BLAST (Invitrogen) by use of Cell-fectin (Invitrogen) as per the manufacturer's instructions. Supernatants were prepared by culturing stable clones in serumfree medium lacking antibiotics supplemented with $500 \mathrm{mM}$ copper sulfate to induce transgene expression. After $72 \mathrm{~h}$, supernatants were collected, filtered, and frozen. IFN- $\beta$ biologic activity was ascertained by plaque reduction assay on Vero cells with vesicular stomatitis virus expressing green fluorescent protein (VSV-GFP). The supernatant dilution yielding a cytopathic effect (CPE) of 50\% was determined as containing $1 \mathrm{U}$ IFN/mL.

\section{Cell culture and viruses}

Human embryonic lung (HEL) fibroblasts and Vero kidney epithelial cells (American Type Culture Collection, Rockville, MD) were maintained in Dulbecco's modified Eagle medium (DMEM) supplemented with $10 \%$ and $5 \%$ fetal bovine serum (FBS), respectively. Beas-2B lung epithelial cells (obtained from $S$. Erzurum, Lerner Research Institute) were maintained in LHC-9 medium (Biosource, Camarillo, CA) with 10\% FBS. Culture flasks were prepared with coating medium $(0.01 \mathrm{mg} / \mathrm{mL}$ fibronectin, Calbiochem, La Jolla, CA; $0.03 \mathrm{mg} / \mathrm{mL}$ Vitrogen 100, Cohesion, Palo Alto, CA; and $0.01 \mathrm{mg} / \mathrm{mL}$ bovine serum albumin [BSA] dissolved in LHC-9 basal medium). All media were supplemented with $1 \%$ L-glutamine and $1 \%$ penicillin/ streptomycin. VSV-GFP was propagated on Vero cells.

\section{VSV-GFP plaque reduction assays}

Cells were seeded in 12-well dishes. Following the indicated treatment, cells were washed with warm $\left(37^{\circ} \mathrm{C}\right) \mathrm{PBS}$ and in- cubated with 4080 plaque-forming units (PFU)/well of VSVGFP for $40 \mathrm{~min}$ in serum-free medium. The viral inoculum was removed and replaced with DMEM containing $1 \%$ methylcellulose. GFP fluorescence intensity was measured $24 \mathrm{~h}$ later on a Typhoon Trio (GE Healthcare) and quantified using the ImageQuant TL software.

\section{Generation of smoke-conditioned medium and treatment of cells}

Smoke-conditioned medium (SCM) was generated according to a protocol that has been described in detail by Bernhard and others (2004). Briefly, 2 cigarettes (1R3 reference cigarettes, Tobacco and Health Research Institute, University of Kentucky) were bubbled through $8 \mathrm{~mL}$ culture medium at a rate of $35 \mathrm{~mL}$ in $2 \mathrm{sec}$, every $28 \mathrm{sec}$. The resultant SCM was filtersterilized and subsequently considered to have a concentration of $100 \%$. SCM was diluted to the desired concentration in culture medium. SCM was made fresh for each experiment, unless otherwise indicated.

For aged-SCM studies, SCM was prepared as described and diluted to the desired concentrations in culture medium. Diluted SCM was allowed to age at $4^{\circ} \mathrm{C}$ for 3 days. Following incubation of cells with varying concentrations of SCM for $2 \mathrm{~h}$, cells were carefully washed two times with warm $\left(37^{\circ} \mathrm{C}\right) \mathrm{PBS}$, placed in fresh medium, and treated with the indicated ligand for $6 \mathrm{~h}$ (except for immunofluorescence studies, when treatment with the indicated ligand was for $2 \mathrm{~h}$ ).

\section{$R N A$ extraction and real-time quantitative reverse transcriptase polymerase chain reaction ( $R T-P C R)$}

RNA was isolated from fibroblasts that were cultured with varying concentrations of SCM for $2 \mathrm{~h}$, followed by the addition of the indicated dose of polyI:C for $6 \mathrm{~h}$, using Trizol reagent (Invitrogen) according to the manufacturer's protocol. RNA was DNase treated using DNA-free as per the manufacturer's specifications (Ambion, Austin, TX). RNA was quantified using the Agilent 2100 Bio-Analyzer (Agilent, Santa Clara, CA). Total RNA (150 ng) was reverse transcribed with $100 \mathrm{U} \mathrm{Su}-$ perscript II (Invitrogen) in a total reaction volume of $20 \mu \mathrm{L}$. A random hexamer primer was used to synthesize cDNA at $42^{\circ} \mathrm{C}$ for $50 \mathrm{~min}$, followed by $15 \mathrm{~min}$ incubation at $70^{\circ} \mathrm{C}$. Real-time quantitative PCR was performed in triplicate in a total volume of $25 \mu \mathrm{L}$ using Universal PCR Master Mix (Applied Biosystems, Foster City, CA). Primers for ISG15, IRF-7, and 18s along with FAM-labeled probes were purchased from Applied Biosystems. PCR was run in the ABI PRISM 7900HT Sequence Detection System using the Sequence Detector Software version 2.2 (Applied Biosystems). Data were analyzed using the delta, delta $\mathrm{Ct}(\Delta \Delta \mathrm{Ct})$ method. Specifically, gene expression was normalized to the housekeeping gene (18s) and expressed as fold change over the control group ( $0 \%$ SCM, no polyI:C).

\section{Immunofluorescence}

Semiconfluent HEL fibroblasts or Beas-2B epithelial cells were seeded on glass coverslips and treated as indicated. Cells were fixed with $4 \%$ paraformaldehyde, permeabilized with $0.1 \%$ Triton $\mathrm{X}-100$, and blocked overnight at $4^{\circ} \mathrm{C}$ in PBS- $0.02 \%$ Tween-20 containing $2 \%$ goat serum (NF- $\kappa$ B staining) or $3 \%$ 
goat serum/BSA (IRF-3 staining). NF- $\kappa$ B (p65) and IRF-3 were detected using SC-372 (Santa Cruz, Santa Cruz, CA) at a dilution of 1:500 and 15-02 (a generous gift from M. David, UCSD) at a dilution of 1:2500, respectively. For detecting phosphorylated Stat1 (Stat1P), HEL cells were rinsed in ice-cold PBS and fixed in $4 \%$ paraformaldehyde, permeabilized with $\mathrm{MeOH}$ :acetone (1:1) and blocked in 10\% fish gelatin (Sigma, St. Louis, MO) in Tris-buffered saline (TBS) with $0.1 \%$ Tween for $1 \mathrm{~h}$ at ambient temperature. Stat1P was then detected using antihuman pTyr(701) Stat1 (Cell Signaling Technologies, Danvers, MA) at a dilution of $1: 100$ overnight at $4^{\circ} \mathrm{C}$. For all experiments, a secondary antibody dilution of 1:500 (NF- $\kappa$ B), 1:400 (IRF-3), or 1:100 (Stat1P) of a Cy3-conjugated Affini Pure $\mathrm{F}\left(\mathrm{ab}^{\prime}\right)_{2}$ fragment donkey antirabbit IgG was used (Jackson ImmunoResearch Laboratories, West Grove, PA). The total number of cells was determined by staining with Hoechst 33342 (Sigma). Images were captured on a Leica DM-IRE2 inverted microscope. Nuclear accumulation of p65 and Stat1P was calculated from three independent experiments with a total of nine random fields of view for each treatment, whereas nuclear accumulation of IRF-3 was calculated from one experiment, representative of three independent experiments, with a total of three random fields of view for each treatment.

\section{Preparation of nuclear and cytosolic proteins}

Nuclear and cytosolic proteins were extracted using a modification of previously described methods (Schreiber and others 1990; Andrews and Faller 1991). Briefly, treated cells were washed twice in ice-cold $1 \times$ PBS and once in ice-cold $0.2 \times$ PBS before the addition of $225 \mu \mathrm{L}$ hypotonic buffer A $(10 \mathrm{mM}$ HEPES, pH 7.3, $10 \mathrm{mM} \mathrm{KCl,} 1.5 \mathrm{mM} \mathrm{MgCl}_{2}, 5 \mathrm{mM} \mathrm{NaF}, 0.5$ $\mathrm{mM}$ DTT, $1 \mathrm{mM}$ PMSF, $1 \times$ protease inhibitor cocktail, $1 \mathrm{mM}$ $\mathrm{Na}_{3} \mathrm{VO}_{4}$ ). The cells were scraped gently and transferred to a 1.5-mL tube, vortexed briefly at half speed, and incubated on ice for $10 \mathrm{~min}$. Buffer A supplemented with 5\% Triton X-100 $(50 \mu \mathrm{L})$ was added, and cells were vortexed for $10 \mathrm{sec}$ at half speed. Tubes were centrifuged at $12,000 \times g$ for 3 min at $4^{\circ} \mathrm{C}$. The supernatant containing cytoplasmic proteins was transferred to a fresh tube. The pellet was washed once in buffer A prior to resuspension in $50 \mu \mathrm{L}$ high salt buffer $\mathrm{C}(20 \mathrm{mM}$ HEPES, pH 7.3, 25\% glycerol, $420 \mathrm{mM} \mathrm{NaCl}, 1.5 \mathrm{mM} \mathrm{MgCl}_{2}$, 0.2 mM EDTA, pH 8.0, 5 mM NaF, 0.5 mM DTT, 1 mM PMSF, $1 \times$ protease inhibitor cocktail, $1 \mathrm{mM} \mathrm{Na}_{3} \mathrm{VO}_{4}$ ) for $30 \mathrm{~min}$ on ice. The nuclear extracts were cleared by centrifugation for $15 \mathrm{~min}$ at $12,000 \times \mathrm{g}$ at $4^{\circ} \mathrm{C}$. Protein quantification was performed with the Bradford assay kit (Bio-Rad Laboratories, Hercules, CA).

\section{Western blot analysis and quantification}

Cytosolic or nuclear protein $(20 \mu \mathrm{g})$ was electrophoresed on a $10 \%$ denaturing SDS gel and transferred onto nitrocellulose membranes (Amersham, Arlington Heights, IL) using a semidry transfer apparatus at $300 \mathrm{~mA}$ for $1 \mathrm{~h}$. All blots were blocked in 5\% skim milk in TBS at ambient temperature for $1 \mathrm{~h}$. Antihuman pTyr(701) Stat1 (Cell Signaling Technologies) and antihuman actin (Santa Cruz) primary antibodies were used at a dilution of 1:1000 in 5\% BSA in TBS-Tween (0.1\%). Blots were then incubated with the corresponding horseradish peroxidase (HRP)-conjugated secondary antibody and visualized using an enhanced chemiluminescence system (ECLplus kit,
Amersham). For quantification, blots were scanned using the Typhoon Trio, and band intensities were quantified using ImageQuant TL software. Actin was used as an internal control, and Stat1P band intensities were standardized to the corresponding actin band for each lane. Stat1P actin ratios from treated samples were compared to untreated samples and reported as a $\%$ of untreated control, with cytoplasmic treated samples compared to cytoplasmic untreated controls and nuclear treated samples compared to nuclear untreated controls.

\section{Glutathione treatment}

Glutathione (Sigma) was added to cell cultures 30 min prior to the experiment at a concentration of $1 \mathrm{mM}$. During SCM exposure, as well as treatment with polyI:C or IFN- $\beta$, the glutathione was also present at $1 \mathrm{mM}$.

\section{Data analysis}

Data were expressed as means \pm standard error of the mean (SEM) unless otherwise indicated. Statistical analysis was performed using a one-way analysis of variance (ANOVA) with a Tukey's post hoc test with Sigma Stat 2.03.

\section{RESULTS}

\section{SCM compromises polyI: $C$-mediated intracellular antiviral defense mechanisms in HEL fibroblasts and Beas-2B epithelial cells}

To investigate the impact of cigarette smoke on polyI:C-mediated antiviral intracellular signaling events (Fig. 1A), HEL fibroblasts were cultured with varying concentrations of SCM, followed by the addition of a minimal dose of polyI:C (Fig. $2 \mathrm{~A}$ ). To exclude the possibility that SCM affected the entry of polyI:C, cells were washed extensively before polyI:C treatment. In these experiments, an antiviral state is defined as a cellular environment that restricts viral replication and spread, and is determined by a standard plaque reduction assay using VSVGFP. Because an endogenous viral promoter drives GFP expression, fluorescence intensity is a direct measure of viral replication. Treating HEL fibroblasts with $15 \mu \mathrm{g} / \mathrm{mL}$ polyI:C is able to induce an antiviral state capable of preventing VSV-GFP replication (+ polyI:C, 0\% SCM) (Fig. 2B; data not shown). When cultured in the presence of increasing concentrations of SCM, polyI:C-treated HEL fibroblasts were no longer protected against VSV-GFP infection in a dose-dependent manner. SCM alone did not affect the infectivity of VSV-GFP at any of the concentrations tested (data not shown).

Similar to the studies done in fibroblasts, we also assessed whether SCM suppresses induction of an antiviral state in another biologically relevant cell type. We observed that Beas-2B epithelial cells were more sensitive than fibroblasts to polyI:C and entered an antiviral state at a markedly lower concentration of polyI:C $(0.1 \mu \mathrm{g} / \mathrm{ml})$ (data not shown). At this minimal concentration of polyI:C, SCM suppressed induction of an antiviral state in Beas-2B cells, allowing VSV replication (Fig. 2C). Although the effect of SCM on induction of an antiviral state in Beas-2B appeared to be less pronounced than in fibroblasts, the full effect of cigarette smoke on epithelial cells may have been masked by an observed decrease in VSV-GFP fluores- 
A
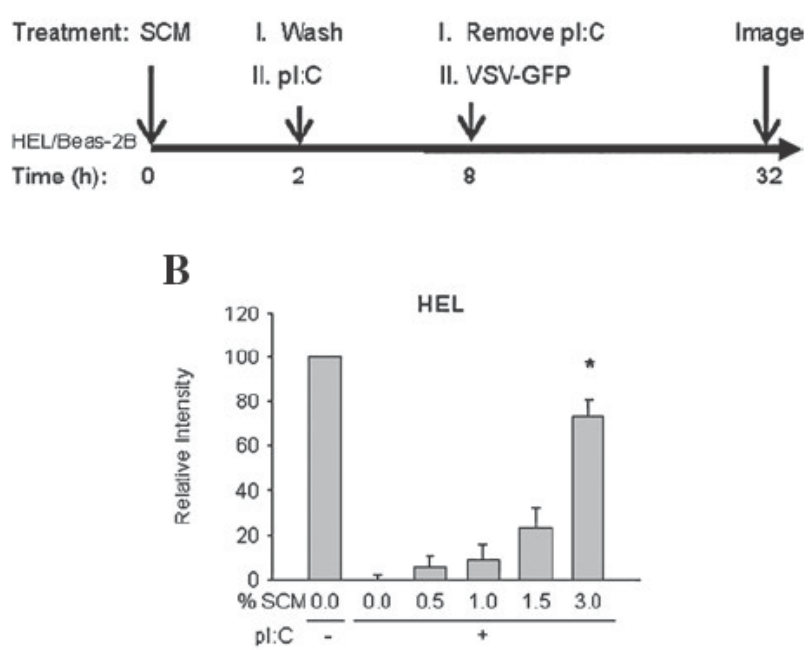

C

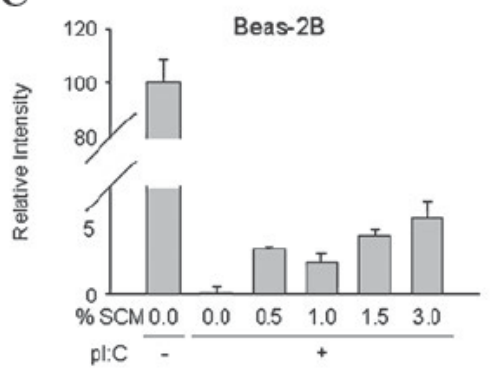

FIG. 2. Effect of SCM on the response of HEL fibroblasts and Beas-2B epithelial cells to a low dose of polyI:C. (A) HEL fibroblasts or Beas-2B epithelial cells were treated with varying concentrations of SCM. Subsequently, cells were extensively washed and either left untreated or treated with $15 \mu \mathrm{g} / \mathrm{mL}$ (HEL) or $0.1 \mu \mathrm{g} / \mathrm{mL}$ (Beas2B) of polyI:C. Standard plaque reduction assays were performed using VSV-GFP, and the relative signal intensity of GFP to untreated samples was determined for fibroblasts and epithelial cells ( $\mathbf{B}$ and $\mathbf{C}$, respectively). (B) The data are representative of three independent experiments performed in duplicate. ${ }^{*} p<0.001$ compared to no SCM in the presence of polyI:C. (C) The data are representative of one of three experiments performed in duplicate and are shown as the mean \pm SD.

cence intensity at $3 \% \mathrm{SCM}$ in the absence of polyI:C stimulation (data not shown), suggesting that cigarette smoke may directly compromise viral replication in Beas-2B cells. Cells were thoroughly washed prior to VSV infection, suggesting that decreased replication was not due to residual components of SCM affecting viral binding and entry.

\section{SCM compromises polyI:C-mediated type I IFN production from HEL fibroblasts and Beas- $2 B$ epithelial cells}

We next determined if treating cells with higher concentrations of polyI: $\mathrm{C}$ would overcome the suppressive effects of cigarette smoke and if these cells would be able to elicit the production of an antiviral state. Fibroblasts and epithelial cells were treated with varying concentrations of SCM, followed by the addition of $100 \mu \mathrm{g} / \mathrm{mL}$ polyI:C (Fig. 3A). High dose polyI:C treatment of HEL fibroblasts and Beas-2B epithelial cells, in the presence or absence of SCM, restricts VSV-GFP replication (Fig. 3B and D, respectively), indicating that these cells were able to enter an antiviral state in the presence of SCM.

To assess what impact cigarette smoke has on the production of type I IFN (Fig. 1A), supernatants from fibroblasts and epithelial cells were transferred to naïve Vero cell monolayers to be assayed for the presence of secreted biologically active IFN (Fig. 3C, D). Although Vero cells fail to produce IFN due to a genetic lesion in the IFN locus (Diaz and others 1988; Emeny and Morgan 1979), they respond to human IFN and induce an antiviral state capable of decreasing the replication efficiency of VSV by 5 to 6 logs (Wathelet and others 1992; Mossman and others 2000). Supernatants from fibroblasts and epithelial cells that had been treated with the high dose of polyI: $\mathrm{C}$ were able to induce an antiviral state in Vero cells $(0 \%$ SCM, + polyI:C) (Fig. 3C and E, respectively; data not shown). We observed a significant increase in VSV replication in Vero cell cultures treated with supernatants from HEL fibroblasts and Beas-2B epithelial cells exposed to $3 \%$ SCM (Fig. 3C, E), suggesting that at this concentration, SCM compromises the ability of fibroblasts and epithelial cells to produce type I IFNs. Vero cells treated with the supernatants from minimal dose polyI:C-treated HEL fibroblasts and Beas-2B epithelial cells were not protected from VSV infection, indicating that either no IFN or an undetectable amount was present in those supernatants (data not shown).

\section{HEL fibroblasts and Beas-2B epithelial cells are viable and metabolically active in the presence of SCM}

To ensure that the observed inability of cells to enter an antiviral state in response to a minimal dose of polyI:C and the lack of sufficient biologically active IFN production from these cells in response to high dose polyI:C was a result of compromised antiviral immunity and not an artifact of smoke-induced cell death or altered metabolic activity, we assessed viability and metabolic activity of the HEL fibroblasts and Beas-2B epithelial cells in the context of SCM. HEL fibroblasts were cultured in varying concentrations of SCM; cell viability was assessed by trypan blue dye exclusion, and metabolic activity was assessed by MTT assay. At the SCM concentrations of interest to our studies, no differences were observed in either fibroblast or epithelial viability or metabolic activity (data not shown). Furthermore, a significant decrease in viability was observed only when fibroblasts were treated with at least $25 \%$ SCM, an 8 -fold greater concentration than the one used in the studies, and when epithelial cells were treated with at least $10 \%$ SCM. These findings suggest that the inhibitory effects of SCM on antiviral immunity are not due to decreased cell viability or metabolic activity.

\section{Induction of ISG15 and IRF-7 RNA transcripts in response to polyI: $C$ is reduced in fibroblasts treated with SCM}

To delineate mechanistically the effect of SCM on IFN signaling cascades, we assessed induction of two IFN-stimulated genes, ISG15 and IRF-7. ISG15 is a product of the immediate- 
A

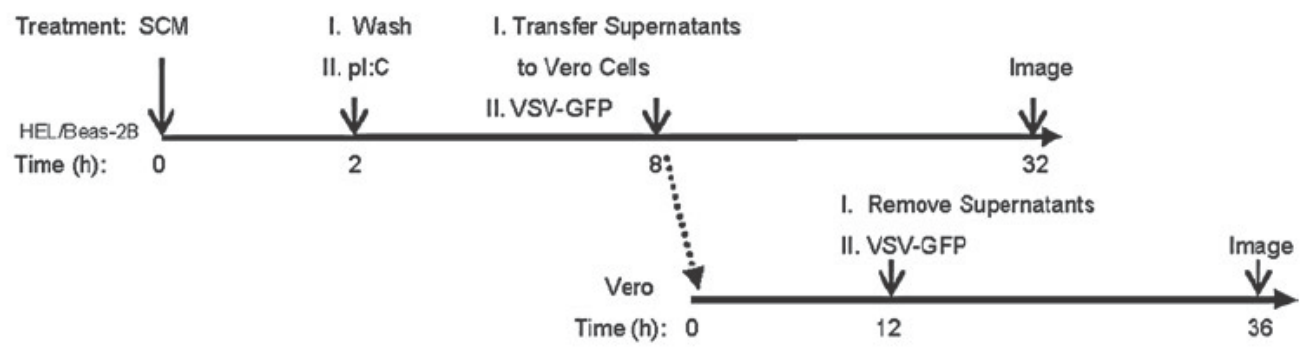

B

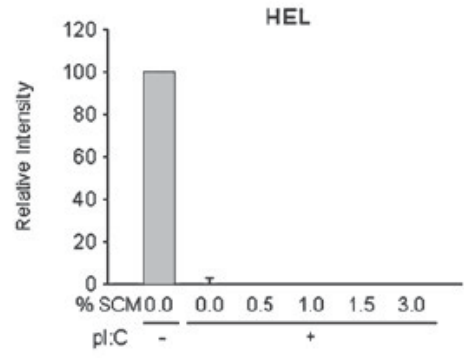

D

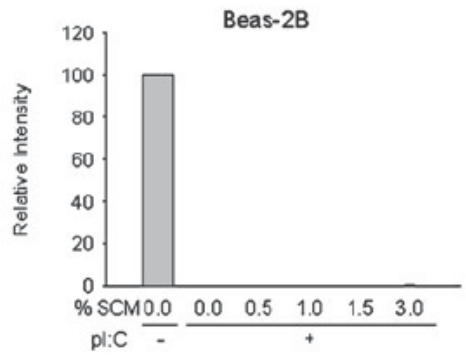

C

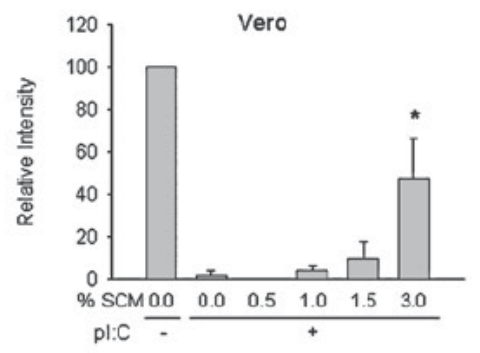

E

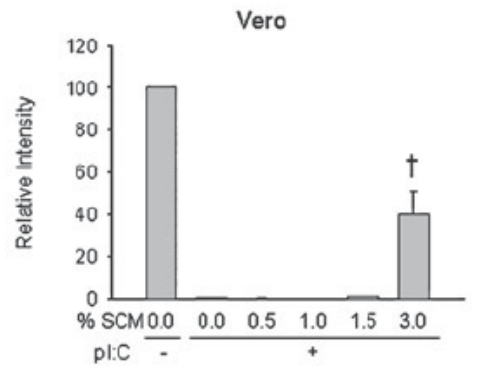

FIG. 3. Effect of SCM on the response of HEL fibroblasts and Beas-2B epithelial cells to a high dose of polyI:C and on the production of IFN. (A) HEL fibroblasts or Beas-2B epithelial cells were treated with varying concentrations of SCM. The cells were subsequently either left untreated or treated with $100 \mu \mathrm{g} / \mathrm{mL}$ polyI:C. Standard plaque reduction assays were performed using VSV-GFP, and the signal intensity of GFP relative to untreated samples was determined for (B) HEL fibroblasts and (D) Beas-2B epithelial cells. Supernatants from HEL fibroblasts or Beas-2B cells were transferred to naïve Vero cell monolayers. Standard plaque reduction assays were performed using VSV-GFP, and the relative signal intensity of GFP was measured: (C) supernatants from HEL; (E) supernatants from Beas-2B. ${ }^{*} p<0.023 ; \dagger p=0.003$, compared to no SCM in the presence of polyI:C. The data are representative of three independent experiments performed in duplicate.

early events leading to activation of the $I F N-\beta$ gene. Synthesis of ISG15 is IRF-3 dependent but can be IFN independent. Alternatively, IRF-7 is a product of the inductive phase, whose synthesis in nonimmune cells, such as fibroblasts and epithelial cells, is dependent on the production of IFN- $\beta$ (Sato and others 2000). Real-time quantitative RT-PCR analysis revealed that in HEL fibroblasts treated with a low dose of polyI:C (15 $\mu \mathrm{g} / \mathrm{mL}$ ), in the absence of SCM, both ISG15 and IRF-7 transcript accumulation increased approximately 8-10-fold over untreated samples (- polyI:C, 0\% SCM) (Fig. 4A, B). Consistent with the biologic VSV plaque reduction assay, ISG15 and IRF-7 transcript accumulation was reduced at 3\% SCM compared with $0 \%$ SCM.

In response to high dose polyI:C (100 $\mu \mathrm{g} / \mathrm{mL})$, in the absence of SCM, ISG15 transcript accumulation in HEL fibroblasts increased approximately 30 fold over untreated samples
(+ polyI:C, 0\% SCM) (Fig. 4C), whereas IRF-7 transcript accumulation increased approximately 20 -fold over untreated samples (Fig. 4D). At 3\% SCM, ISG15 transcript accumulation decreased to approximately 8 -fold over untreated samples (Fig. $4 C$ ), whereas IRF-7 transcript accumulation decreased to $<5$ fold over untreated samples (Fig. 4D). ISG15 and IRF-7 expression was significantly decreased in the presence of $3 \%$ SCM when compared with polyI:C-stimulated samples in the absence of SCM (Fig. 4C, D).

\section{$N F-\kappa B$ and IRF-3 nuclear translocation is affected in the presence of $S C M$}

Given that in fibroblasts and epithelial cells NF- $\kappa \mathrm{B}$ is required for the production of IFN, and IRF-3 is essential for IFNdependent and IFN-independent antiviral responses, we next 
A

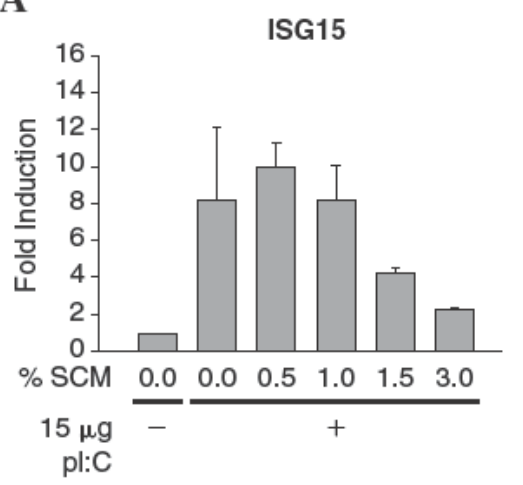

C

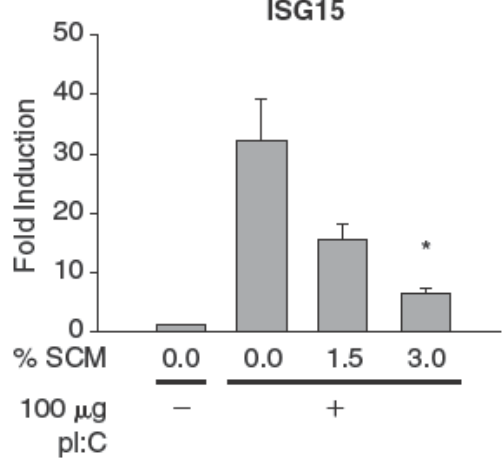

B

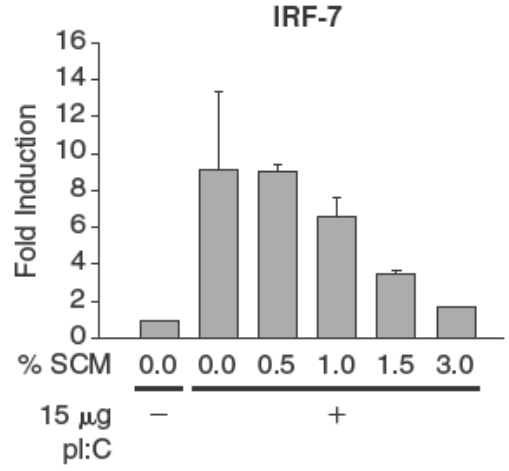

D

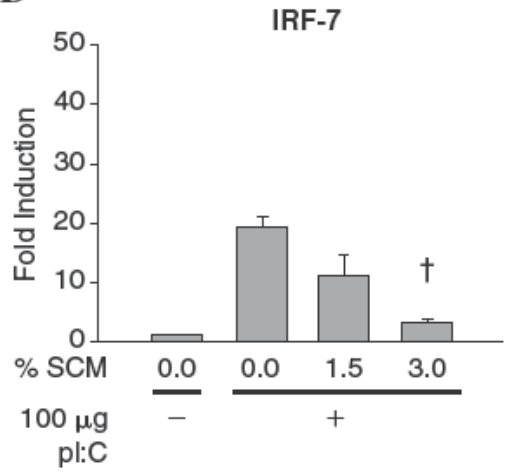

FIG. 4. Effect of SCM on the induction of ISG15 and IRF-7 in response to polyI:C treatment. HEL fibroblasts were exposed to varying concentrations of SCM. Cells were subsequently either left untreated (-) or treated (+) with $15 \mu \mathrm{g} / \mathrm{mL}(\mathbf{A}$ and B) or $100 \mu \mathrm{g} / \mathrm{mL}$ (C and D) of polyI:C. Fold induction of ISG15 (A and C) and IRF-7 (B and D), normalized to levels of a housekeeping gene in the same sample and compared with untreated cells, was determined by real-time quantitative RT-PCR. The data are representative of three independent experiments performed in triplicate. ${ }^{*} p<0.007 ; \dagger p=0.003$, compared to no SCM in the presence of polyI:C.

determined whether SCM affects the activation of these key signaling molecules in response to polyI:C. We determined by immunofluorescence if SCM inhibited the activation of NF- $\kappa$ B following stimulation with polyI:C in HEL and Beas-2B cells (Fig. 5A and B, respectively). Greater than $90 \%$ of the nuclei stained positive for the p65 subunit of the NF- $\kappa$ B complex in both HEL and Beas-2B cells after stimulation with TNF- $\alpha$ (data not shown), whereas approximately $25 \%$ of HEL (Fig. 5A) and $70 \%$ of Beas-2B (Fig. 5B) nuclei stained positive after stimulation with polyI: $\mathrm{C}$. We observed a significant decrease in NF$\kappa \mathrm{B}$ nuclear translocation in response to polyI:C stimulation in fibroblasts and epithelial cells cultured in SCM (Fig. 5A and $B$, respectively). Culture of cells in SCM alone did not induce $\mathrm{NF}-\kappa \mathrm{B}$ nuclear translocation in either cell line.

We next investigated if IRF-3 nuclear translocation was decreased following polyI:C stimulation in cells treated with SCM. Although we were unable to detect IRF-3 nuclear translocation after stimulation with polyI: $\mathrm{C}$ in HEL cells for technical reasons (data not shown), approximately $80 \%$ nuclear translocation of IRF-3 was observed in Beas-2B cells treated with polyI:C (Fig. 5C). Similar to the decrease observed in the translocation of NF- $\kappa$ B, we observed decreased IRF-3 nuclear translocation in response to polyI: $\mathrm{C}$ in Beas-2B cells cultured in SCM (Fig. 5C). IRF-3 nuclear translocation was not observed in cells treated with SCM alone.
SCM compromises IFN-mediated intercellular antiviral defense mechanisms in HEL fibroblasts and Beas- $2 B$ epithelial cells

We have demonstrated, to this point, that cigarette smoke impairs intracellular antiviral signaling events (Fig. 1A), which lead to the production of an antiviral state in fibroblasts and epithelial cells in response to polyI:C. Cigarette smoke has also been shown to impair production of type I IFN in response to a high dose of polyI: $\mathrm{C}$, but the consequence of this impairment to intercellular antiviral signaling (Fig 1B) has not yet been addressed. To determine if SCM affects intercellular IFN- $\beta$ signaling, we treated fibroblasts with $3 \% \mathrm{SCM}$ and subsequently washed and stimulated them with varying amounts of IFN- $\beta$ (Fig. 6). Treatment of fibroblasts with $50 \mathrm{U} / \mathrm{mL}$ IFN- $\beta$ did not allow VSV-GFP to replicate. When fibroblasts were treated with 12.5 and $25 \mathrm{U} / \mathrm{mL}$ IFN- $\beta$, in the presence of SCM, significant VSV-GFP replication was observed, suggesting that these cells were no longer able to enter an antiviral state.

\section{Induction of ISG15 and IRF-7 RNA transcripts in response to IFN- $\beta$ is reduced in fibroblasts treated with SCM}

To further examine if cigarette smoke also impaired the induction of key ISGs, namely, ISG15 and IRF-7, in response to 
$\mathbf{A}$

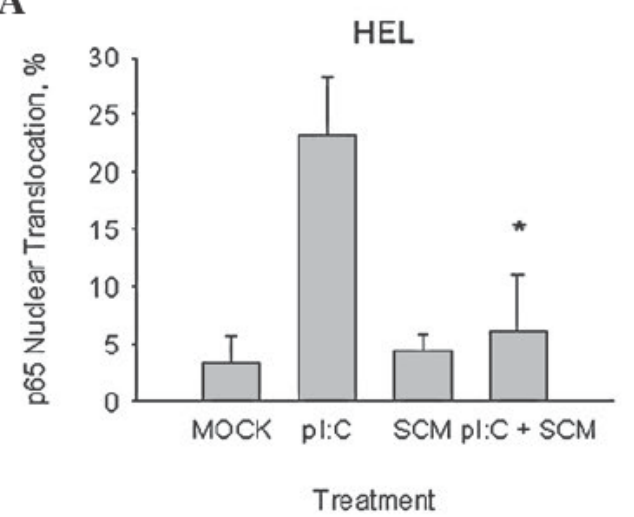

B

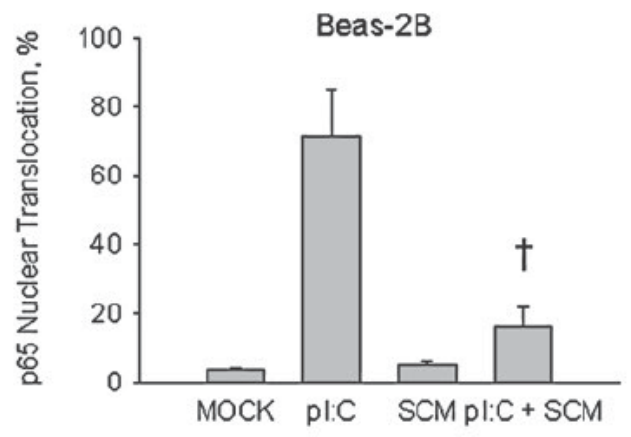

Treatment

C

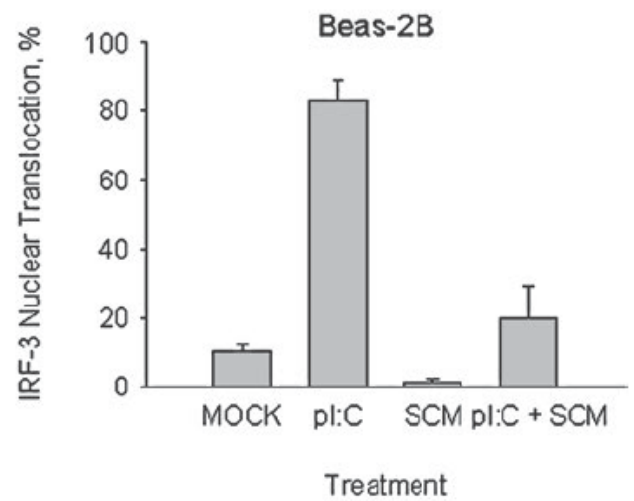

FIG. 5. Effect of SCM on NF- $\kappa$ B and IRF-3 nuclear translocation in fibroblast and epithelial cells. HEL fibroblasts and Beas-2B epithelial cells were either left untreated (MOCK) or treated with SCM. Subsequently, cells were further left untreated or treated with $15 \mu \mathrm{g} / \mathrm{mL}$ (HEL) or $10 \mu \mathrm{g} / \mathrm{mL}$ (Beas2B) of polyI:C. Immunofluorescence was performed using an antibody directed against the p65 subunit of NF- $\kappa$ B (A and B) or an antibody directed against IRF-3 (C). The percentage of cells that were nuclear $\mathrm{p} 65$ positive in HEL (A) and Beas-2B (B) was calculated from three independent experiments. ${ }^{*} p=$ $0.047 ; \dagger p=0.004$ compared with polyI:C. (C) The percentage of cells that were nuclear IRF-3 positive was calculated from one representative experiment of three and is shown as the mean $\pm \mathrm{SD}$.

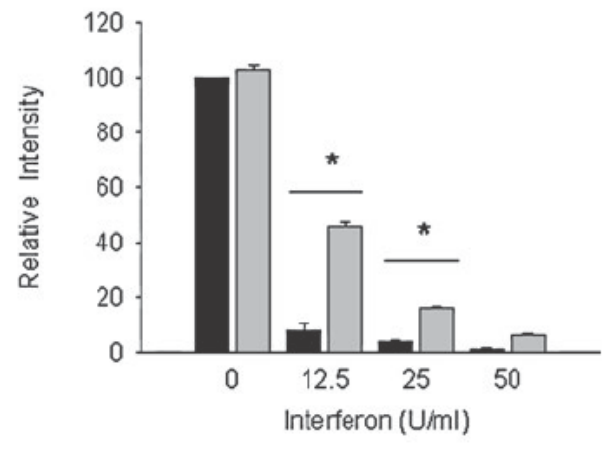

FIG. 6. Effect of SCM on the response of fibroblasts to IFN$\beta$ treatment. HEL fibroblasts were either left untreated (black bars) or treated with $3 \%$ SCM (gray bars). Subsequently, cells were washed and treated with the indicated amounts of IFN- $\beta$. Standard plaque reduction assays were performed using VSVGFP, and signal intensity of GFP relative to untreated samples was determined. The data are representative of three independent experiments performed in duplicate. ${ }^{*} p<0.001$.

IFN- $\beta$ stimulation, we cultured cells in varying concentrations of SCM. Subsequently, cells were washed and stimulated with $25 \mathrm{U} / \mathrm{mL}$ IFN- $\beta$. Real-time quantitative RT-PCR analysis revealed that in response to IFN- $\beta$, in the absence of SCM, HEL fibroblast ISG15 and IRF-7 transcript accumulation increased approximately 30-40-fold over untreated samples (+ polyI:C, 0\% SCM) (Fig. 7). Consistent with the biologic VSV plaque reduction assay, ISG15 and IRF-7 transcript accumulation was reduced at 3\% SCM compared with no SCM in the presence of IFN- $\beta$.

\section{Nuclear accumulation of Stat1P in response to IFN- $\beta$ is impaired by SCM}

To examine if cigarette smoke impairs the second wave of the antiviral response, initiated by secreted IFN- $\beta$ binding its receptor and causing activation of Stat molecules through JakStat signaling pathways (Fig. 1B), fibroblasts were treated with $3 \%$ SCM. Cells were subsequently washed and stimulated with $25 \mathrm{U} / \mathrm{mL}$ IFN- $\beta$. Western blot analysis of Stat1P protein from cytoplasm and nuclear extracts demonstrated that stimulation of fibroblasts with IFN- $\beta$ increased the intensity of protein relative to untreated (Mock) samples (Fig. 8A, B). A significant decrease in the intensity of nuclear Stat1P protein was observed in IFN- $\beta$-stimulated cells treated with SCM. Furthermore, we assessed by immunofluorescence if SCM inhibited the nuclear accumulation of Stat1P following stimulation with IFN- $\beta$ (Fig. 8C). Greater than $40 \%$ and $75 \%$ of fibroblast nuclei stained positive for Stat1P after stimulation with 25 and $50 \mathrm{U} / \mathrm{mL}$ of IFN- $\beta$, respectively. We observed a significant decrease in Stat1P nuclear translocation in response to IFN- $\beta$ stimulation in fibroblasts cultured in SCM. Culture of cells in SCM alone did not induce Stat1P nuclear translocation.

\section{Effects elicited by SCM are reversible}

To investigate whether the impact of cigarette smoke on antiviral immunity is reversible, HEL cells were cultured in SCM for $2 \mathrm{~h}$ and subsequently placed in clean medium for $24 \mathrm{~h}$. Fol- 
A

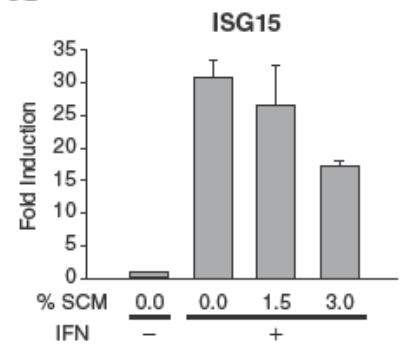

B

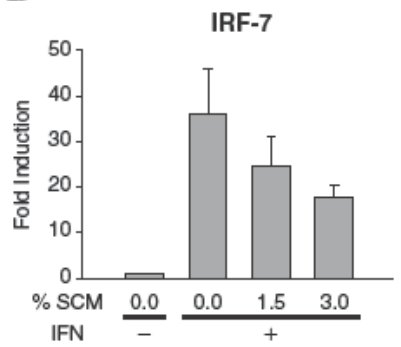

FIG. 7. Effect of SCM on the induction of ISG15 and IRF-7 in response to IFN- $\beta$ treatment. HEL fibroblasts were exposed to varying concentrations of SCM. Cells were subsequently either left untreated (-) or treated (+) with $25 \mathrm{U} / \mathrm{mL}$ IFN- $\beta$. Fold induction of ISG15 (A) and IRF-7 (B), normalized to levels of a housekeeping gene in the same sample and compared with untreated cells, was determined by real-time quantitative PCR. The data are representative of three independent experiments performed in triplicate.

lowing this, cells were stimulated with $15 \mu \mathrm{g} / \mathrm{mL}$ polyI:C and subjected to VSV plaque reduction assay. These experiments were run concurrently with and compared to the data that was reported in Figure 2. Compared to cells that were treated with polyI:C immediately after exposure to SCM, no VSV replication was observed in cells given $24 \mathrm{~h}$ recovery time prior to polyI:C stimulation (Fig. 9A). A statistically significant difference was observed at 3\% SCM between the two treatment groups, suggesting that the impact of cigarette smoke on induction of an antiviral state is reversible.

Furthermore, to examine if aged SCM would equally suppress innate antiviral immunity, fibroblasts were treated with varying concentrations of fresh or aged SCM. Compared with cells that were stimulated with polyI:C and treated with fresh SCM, aged SCM-treated cells stimulated with polyI: $\mathrm{C}$ had significantly less VSV-GFP replication (Fig. 9B), indicating that a component within the SCM was depleted during the aging process.

Unstable free oxygen radicals may play a significant role in the observed defects in polyI:C-mediated and IFN- $\beta$-mediated antiviral immunity in the presence of $S C M$

We examined the role of glutathione in reversing the effects of SCM on polyI:C-mediated and IFN- $\beta$-mediated antiviral responses. In polyI:C-stimulated fibroblasts, glutathione treatment significantly decreased the effects of 3\% SCM on induction of an antiviral state (Fig. 10A). Similarly, fibroblasts treated with $12.5 \mathrm{U} / \mathrm{mL}$ IFN- $\beta$ in the presence of SCM and glutathione had significantly less VSV-GFP replication (Fig. 10B). These data suggest that unstable free oxygen radicals play an important role in the impaired ability of cells to mount an antiviral response in the presence of SCM.

\section{DISCUSSION}

Cigarette smoking has been associated with an increased risk of respiratory tract infections in young healthy smokers as well as patients suffering from smoking-related illnesses, such as chronic obstructive pulmonary disease (COPD) (Arcavi and Benowitz 2004; Pauwels and others 2001). These observations suggest that smoking may in fact impair respiratory host defenses. The objective of our study was to specifically examine the mechanistic impact of cigarette smoke on type I IFN-mediated antiviral immune responses.

Epithelial cells and fibroblasts are often the first nonimmune cells within the respiratory tract to encounter viral pathogens and are integral in the initiation of an innate and subsequent adaptive immune response through the expression of type I IFNs (Sen 2001; Stark and others 1998). Therefore, to model the effect of cigarette smoking on antiviral defense mechanisms, we cultured HEL and Beas-2B cells in cigarette SCM. In initial experiments using SCM, we performed time courses and dose-responses to establish conditions that did not affect cell viability or metabolic activity. Whereas concentrations $>10 \%$ SCM were able to substantially affect cell viability, lower concentrations, such as those used in this study, did not affect viability or metabolic activity. Thus, the effects elicited by SCM in our studies are not a result of the cytotoxic effects of cigarette smoke.

We recently reported a novel model in which epithelial cells and fibroblasts are primed to respond to low levels of viral infection by activating IRF-3 in the absence of detectable biologically active IFN production (Paladino and others 2006). In turn, a small subset of ISGs is produced, which ultimately leads to the production of an antiviral state. The fact that viral infection has been controlled within the primary infected cell is important, as unnecessary cytokine secretion will cause the infiltration of immune cells to the site of infection, which may lead to tissue damage. In this model, we propose that when a threshold of activation is surpassed, both IRF- 3 and NF- $\kappa$ B become activated, leading to an intercellular defense strategy that includes the activation of Jak-Stat signaling pathways by ligation of secreted IFN- $\beta$ with its receptor. In this study, we used two different doses of a dsRNA mimic, polyI:C, to examine to what extent cigarette smoke alters intracellular (low dose) and intercellular (high dose) IFN-mediated antiviral signaling. In addition, we used human IFN- $\beta$ to further examine the intercellular signaling properties of this cytokine in the presence of cigarette smoke.

In a series of titration studies, we determined the minimal dose of polyI: $\mathrm{C}$ required to induce an antiviral state in both HEL and Beas-2B cells. Epithelial cells were able to enter an antiviral state at a markedly lower dose of polyI:C than were fibroblasts. This may reflect intrinsic differences between fibroblasts and epithelial cells; alternatively, the first cells to encounter viral pathogens within the respiratory tract are epithelial cells, which may explain their enhanced sensitivity to polyI:C.

In response to minimal dose polyI:C treatment, epithelial cells and fibroblasts were unable to enter an antiviral state in the presence of SCM. Consistent with this, we observed decreases in the level of ISG15 expression, which is associated with protection of fibroblast monolayers. We observed that a circa 8-fold induction of ISG15 in response to low dose dsRNA treatment was associated with protection of a monolayer (compare Fig. 2B with Fig. 4A). Although we did not observe a statistically significant decrease in the fold induction of ISG15 from fibroblasts stimulated with polyI:C and those stimulated 
A
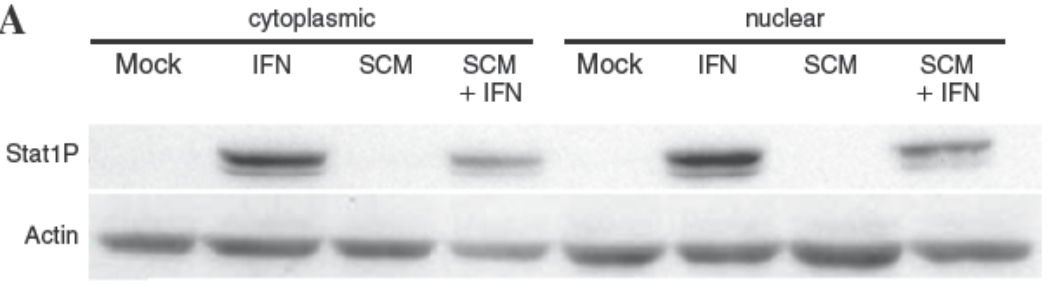

FIG. 8. Effect of SCM on the nuclear accumulation of Stat1P in response to IFN- $\beta$ treatment. (A) Western blot analysis of Stat $1 \mathrm{P}$ and actin protein from cytoplasm and nuclear extracts of HEL fibroblasts that were either left untreated (Mock) or treated with $3 \%$ SCM. Subsequently, cells were washed and stimulated with $25 \mathrm{U} / \mathrm{ml}$ IFN. (B) The intensity of the bands from cytoplasmic (gray bars) or nuclear (black bars) extracts was determined from three independent experiments and is expressed relative to Mock, where Mock is expressed as $100 \% . * p<0.001$. (C) Immunofluorescence was performed on fibroblasts that were either left untreated (black bars) or treated with 3\% SCM (gray bars) and subsequently stimulated with the indicated amounts of IFN- $\beta$. Using an antibody directed against Stat1P, the percentage of cells that were nuclear Stat1P positive in HEL fibroblasts was calculated from three independent experiments. $\uparrow p=0.030 ; \ddagger p=$ 0.007 .
B
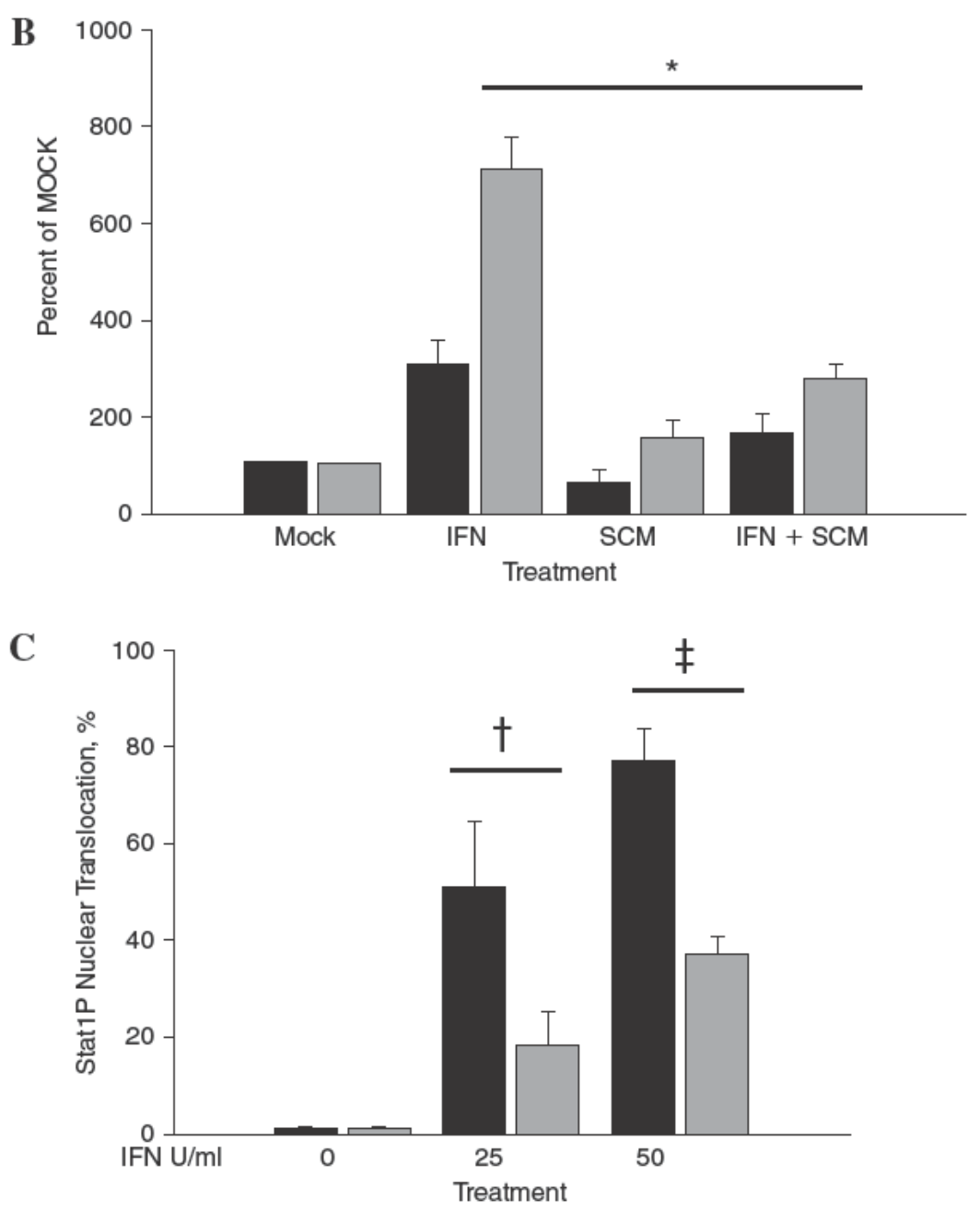

with polyI: $\mathrm{C}$ in the presence of $3 \% \mathrm{SCM}$, if less stringent statistical analyses were performed, a significant decrease in the induction of ISG15 was observed. Similarly, we observed decreased production of IRF-7 in response to low dose polyI:C.

Induction of IRF-7 is IRF-3 dependent and generally requires the production of IFN in nonimmune cells. Despite the fact that we were unable to detect biologically active IFN in the supernatants from low dose polyI:C-treated fibroblasts and epithelial cells (data not shown), we still observed production of IRF-7 transcripts in response to low dose polyI:C, suggesting that either low levels of IFN were produced or that IRF-7 can be induced following IRF-3 activation in these cells. Given that Vero cells are less sensitive to IFN than HEL fibroblasts (Hummel and others 2005), low levels of IFN, sufficient to elicit IRF-7 transcription in HEL fibroblasts, but insufficient to protect Vero cells, were potentially made in response to low dose polyI:C. Consistent with this possibility, some NF- $\kappa$ B activation can be detected in response to low level polyI:C treatment (data not shown). Notably, at the low dose of polyI:C in the presence of SCM, we observed a decrease in the accumulation of IRF-7 transcripts.

The ability of fibroblasts and epithelial cells to produce type I IFN with increasing concentrations of SCM in response to a high dose $(100 \mu \mathrm{g} / \mathrm{mL})$ of polyI:C was shown to be impaired. This was in agreement with previously published work (Sonnenfeld and Hudgens 1986). Additionally, we found that despite the impaired production of type I IFN, fibroblasts and epithelial cells were still able to elicit an antiviral state under these conditions. These findings suggest that despite the decreased production of IFN, a sufficient subset of ISGs was activated to elicit an antiviral state within the treated cells. Consistent with this, despite the presence of SCM, we observed a $>8$-fold induction of ISG15 by quantitative RT-PCR analysis, which corresponded to protection of a monolayer in the biologic VSV-GFP assay (compare Fig. 3B with Fig. 4C). Hence, fold induction of ISG15 seen 
A

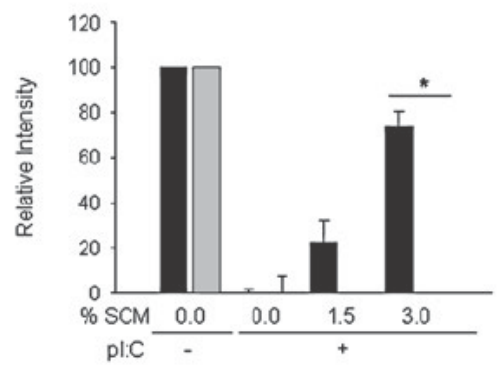

B

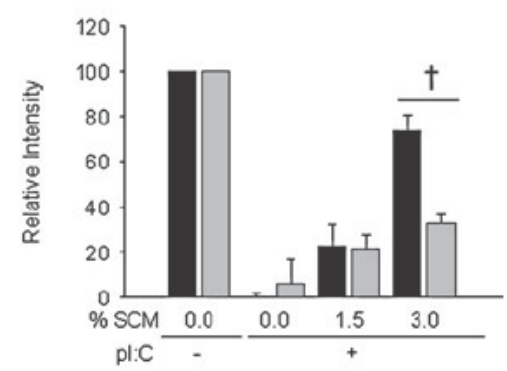

FIG. 9. Effect of recovery time on SCM-treated fibroblasts and effect of treating fibroblasts with aged SCM. (A) HEL fibroblasts were treated with varying concentrations of SCM. Cells were either left untreated $(-)$ or treated $(+)$ with $15 \mu \mathrm{g} / \mathrm{mL}$ polyI:C (black bars) or bathed in fresh medium for 24 hours (gray bars) before being treated similarly with polyI:C. (B) HEL fibroblasts were treated with varying concentrations of fresh (black bars) or aged (gray bars) SCM. Cells were either left untreated ( - ) or treated (+) with $15 \mu \mathrm{g} / \mathrm{mL}$ polyI:C. Following polyI:C stimulation, standard plaque reduction assays were performed using VSVGFP, and the signal intensity of GFP relative to untreated samples was determined. The data are representative of three independent experiments performed concurrently and in duplicate. ${ }^{*} p<0.001 ; \uparrow p=0.015$.

at $3 \% \mathrm{SCM}$ with high dose polyI:C treatment, although significantly decreased, was consistent with levels required for such protection. Furthermore, quantitative RT-PCR data from fibroblasts showed that a circa 20 -fold induction of IRF-7 correlates with protection of a Vero cell monolayer from VSV infection. In our studies, we show that at high doses of polyI:C in fibroblasts, $3 \%$ SCM decreases the accumulation of IRF-7 transcripts to nearly 4-fold. This coincides with the observed decrease in type I IFN production from HEL cells, as evidenced by VSV replication in Vero cells treated with the supernatants from fibroblasts (compare Fig. 3C with Fig. 4D).

In our experiments, it is evident that SCM is impairing both the IFN-dependent and IFN-independent antiviral responses, both of which rely on IRF-3. SCM not only decreased the induction of ISGs but also impaired the activation of IRF-3, as evidenced by decreased nuclear translocation in SCM-treated Beas-2B epithelial cells in response to polyI:C. We were unable to detect IRF-3 nuclear translocation, regardless of polyI:C dose, in HEL fibroblasts. Whether this is due to technical issues or differences in antibody recognition of IRF-3 in HEL fibroblasts and Beas-2B epithelial cells is currently not understood. In addition, SCM decreased polyI:C-mediated NF- $\kappa \mathrm{B}$ nuclear translocation. We are investigating the mechanism(s) by which SCM blocks IRF-3 and NF- $\kappa$ B signal transduction and the effect of SCM on TLR3-mediated and RIG-I-mediated signaling.

To this point, we have demonstrated that cigarette smoke impairs intracellular antiviral signaling in response to a minimal dose of polyI:C. Because cigarette smoke has also been shown to impair production of type I IFN in response to a high dose of polyI:C, the consequences of this to intercellular antiviral signaling needed to be addressed. Thus, fibroblasts were stimulated with human IFN- $\beta$ and were found to be impaired in their ability to mount an antiviral response in the presence of SCM. Consistent with this, we also found decreased induction of ISG15 and IRF-7 in response to IFN- $\beta$ stimulation in the presence of SCM. Upon further analysis of the signaling pathways responsible for the production of an antiviral state in response to IFN- $\beta$ stimulation (Fig. 1B), we found that the nuclear accumulation of phosphorylated Stat1 was also impaired by cigarette smoke in response to stimulation with IFN- $\beta$.

Our data further suggest that the effect of cigarette smoke on innate antiviral defense mechanisms is reversible. Cells regained the ability to enter an antiviral state when allowed $24 \mathrm{~h}$ recovery time after exposure to the cigarette SCM. Interestingly, $24 \mathrm{~h}$ is the minimal amount of time required for cells to be able to regain the ability to enter an antiviral state; in an-
A

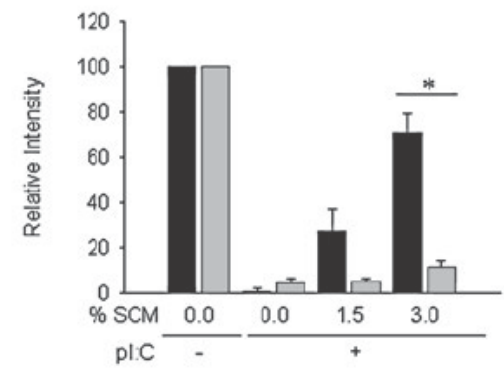

B

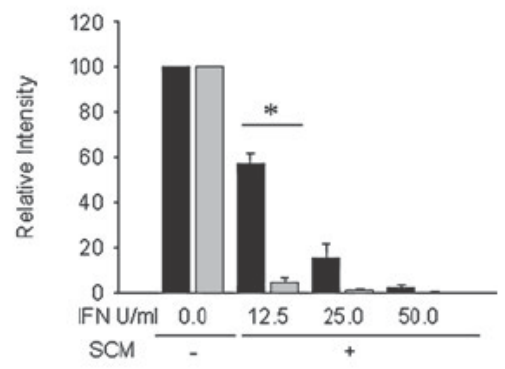

FIG. 10. Effect of the presence of glutathione in SCM-treated fibroblast cultures stimulated with polyI:C or IFN- $\beta$. HEL fibroblasts were pretreated with $10 \mathrm{mM}$ glutathione (gray bars). Cells were exposed to varying concentrations (A) or 3\% (B) SCM in the absence (black bars) or presence (gray bars) of glutathione. Subsequently, cells were washed and stimulated with $15 \mu \mathrm{g} / \mathrm{mL}$ polyI:C (A) or the indicated amounts of IFN- $\beta(\mathbf{B})$ in the absence or presence of glutathione. The data are representative of three independent experiments performed concurrently and in duplicate. ${ }^{*} p<0.001$. 
other series of studies, when only $8 \mathrm{~h}$ recovery time was allowed, cells did not regain the ability to enter an antiviral state (data not shown). These findings are encouraging and may support the many beneficial effects achieved by smoking cessation, the most effective therapy in decreasing the occurrence of many different types of smoking-related diseases. The link between increased viral infections and cigarette smoking has been firmly established in the literature (Arcavi and Benowitz 2004; Aronson and others 1982; Nicholson and others 1999). Studies have conclusively found that there is an increased burden of common colds and influenza infection in smokers compared with nonsmokers (Nicholson and others 1999). It is clear that cessation is effective in the prevention of many smoking-related diseases, and we have provided evidence that smoking cessation may also reverse any inhibitory effects cigarette smoke has on IFN-mediated antiviral immunity.

Glutathione is a ubiquitous tripeptide, which protects cells against oxidants (Rahman and MacNee 1999). Within the lung, the glutathione redox system is one of the most important antioxidant systems (Rahman and others 2006), and cigarette smoke has been well documented to cause changes in oxidant defense responses (MacNee 2000).We show that treatment of cells with glutathione reverses the inability of cells to enter an antiviral state in response to polyI:C and IFN- $\beta$ in the presence of SCM. This finding has important implications, as antioxidant therapy has been suggested as a candidate potential new therapy in the treatment of COPD (Barnes 2005), and a number of antioxidants, including stable glutathione compounds, are now in development for clinical use (Cuzzocrea and others 2001; Chang and others 2003). Collectively, these data suggest a role for unstable free oxygen radicals in the inability of cells to mount an antiviral response to polyI:C and IFN- $\beta$ stimulation in the presence of smoke.

Our data indicate that SCM compromised production of type I IFN and suppressed induction of an antiviral state. These mechanisms may contribute to the increased risk of viral infections often observed in smokers. It is noteworthy that cells were still able to enter an antiviral state at higher concentrations of polyI:C, suggesting that cigarette smoke does not entirely abrogate antiviral responses but rather alters the threshold of activation. This may ultimately lead to delayed immune activation, allowing the virus to replicate and spread. Similar to what we have established with polyI:C, Laan and others (2004) showed that responses to lipopolysaccharide (LPS) in epithelial cells are also impaired in the context of cigarette smoke, indicating that cigarette smoke compromises the sensing of both viral and bacterial agents.

In summary, we have shown that the immediate-early and inductive phases of the type I IFN response to viral stimulus are impaired in cells that have been exposed to cigarette SCM. Moreover, since Jak-Stat signaling is paramount to the amplification phase following production of IFN- $\alpha$ species, cigarette smoke likely affects this phase of the IFN response as well. Thus, our results indicate that the increased burden of viral infection found in smokers compared with nonsmokers may be a result of impaired IFN production by smokers' nonimmune cells within the lung. Furthermore, smoking cessation may contribute to restoring function to those cells that are affected by cigarette smoke. The data suggest a role for unstable free oxygen radicals in mediating the mechanism of impaired type I IFN antiviral response in the context of cigarette smoke. Thus, antioxidant therapy may prove important for overcoming the ef- fects of cigarette smoke-induced defects in IFN-mediated antiviral signaling. This study clearly indicates that cigarette smoke impairs innate antiviral defense mechanisms in vitro, and further studies are being pursued to determine if similar observations can be made in vivo. Because of the persistence of the cigarette smoking habit, understanding the mechanisms by which cigarette smoke alters innate immune function is of paramount importance to developing intervention strategies to restore the early defense mechanisms that are aimed at controlling the spread of infection.

\section{ACKNOWLEDGMENTS}

We acknowledge the secretarial assistance of M. Kiriakopoulos and D. Hoffman. We also appreciate the expert technical support of S. Kianpour, G. Gaschler, D. Cummings, and S. Collins. We thank R. Noyce for helpful discussions. Finally, we thank S. Erzurum and M. David for cell lines and reagents. Research described in this paper was supported in part by the Canadian Institutes of Health Research and by Philip Morris USA Inc. and Philip Morris International. M.R.S. is holder of a CIHR New Investigator Award. K.L.M. is holder of an Rx\&D/CIHR Health Sciences Career Award.

\section{REFERENCES}

Alexopoulou L, Holt AC, Medzhitov R, Flavell RA. 2001. Recognition of double-stranded RNA and activation of NF-kappaB by tolllike receptor 3. Nature 413:732-738.

Andrews N, Faller DV. 1991. A rapid micropreparation technique for extraction of DNA-binding proteins from limiting numbers of mammalian cells. Nucleic Acids Res 19(9):2499.

Arcavi L, Benowitz NL. 2004. Cigarette smoking and infection. Arch Intern Med 164:2206-2216.

Aronson MD, Weiss ST, Ben RL, Komaroff AL. 1982. Association between cigarette smoking and acute respiratory tract illness in young adults. JAMA 248:181-183.

Barnes MC, Streips UN, Sonnenfeld G. 1981. Effect of carcinogens and analogs on interferon induction. Oncology 38:98-101.

Barnes PJ. 2005. New approaches to COPD. Eur Respir Rev 14(94): 2-11.

Bernhard D, Huck CW, Jakschitz T, Pfister G, Henderson B, Bonn GK, Wick G. 2004. Development and evaluation of an in vitro model for the analysis of cigarette smoke effects on cultured cells and tissues. J Pharmacol Toxicol Methods 50:45-51.

Chang LY, Subramaniam M, Yoder BA, Day BJ, Ellison MC, Sunday ME, Crapo JD. 2003. A catalytic antioxidant attenuates alveolar structural remodeling in bronchopulmonary dysplasia. Am J Respir Crit Care Med 167(1):57-64.

Collins SE, Noyce RS, Mossman KL. 2004. Innate cellular response to virus particle entry requires IRF3 but not virus replication. J Virol 78:1706-1717.

Cuzzocrea S, Riley DP, Caputi AP, Salvemini D. 2001. Antioxidant therapy: a new pharmacological approach in shock, inflammation, and ischemia/reperfusion injury. Pharmacol Rev 53(1):135-159.

Daly C, Reich NC. 1993. Double-stranded RNA activates novel factors that bind to the interferon-stimulated response element. Mol Cell Biol 13(6):3756-3764.

Diaz MO, Ziemin S, Le Beau MM, Pitha P, Smith SD, Chilcote RR, Rowley JD. 1988. Homozygous deletion of the alpha- and beta 1-interferon genes in human leukemia and derived cell lines. Proc Natl Acad Sci USA 85:5259-5263. 
Emeny JM, Morgan MJ. 1979. Regulation of the interferon system: evidence that Vero cells have a genetic defect in interferon production. J Gen Virol 43:247-252.

Fitzgerald KA, McWhirter SM, Faia KL, Rowe DC, Latz E, Golenbock DT, Coyle AJ, Liao S-M, Maniatis T. 2003. IKK and TBK1 are essential components of the IRF3 signaling pathway. Nat Immunol 4:491-496.

Guo J, Peters KL, Sen GC. 2000. Induction of the human protein P56 by interferon, double-stranded RNA, or virus infection. Virology 267:209-219.

Hummel JL, Safroneeva E, Mossman KL. 2005. The role of ICPO-Null HSV-1 and interferon signaling defects in the effective treatment of breast adenocarcinoma. Mol Ther 12:1101-1110.

Ishii KJ, Akira S. 2005. Innate immune recognition of nucleic acids: beyond toll-like receptors. Int J Cancer 117:517-523.

Jefferies CA, Fitzgerald KA. 2005. Interferon gene regulation: not all roads lead to Tolls. Trends Mol Med 11:403-411.

Juang YT, Lowther W, Kellum M, Au WC, Lin R, Hiscott J, Pitha P. 1998. Primary activation of interferon A and interferon B gene transcription by interferon regulatory factor 3. Proc Natl Acad Sci USA 95:9837-9842.

Laan M, Bozinovski S, Anderson GP. 2004. Cigarette smoke inhibits lipopolysaccharide-induced production of inflammatory cytokines by suppressing the activation of activator protein-1 in bronchial epithelial cells. J Immunol 173(6):4164-4170.

Lin R, Heylbroeck C, Pitha PM, Hiscott J. 1998. Virus-dependent phosphorylation of the IRF-3 transcription factor regulates nuclear translocation, transactivation potential, and proteasome-mediated degradation. Mol Cell Biol 18:2986-2996.

MacNee W. 2000. Oxidants/antioxidants and COPD. Chest 117(5 Suppl 1):303S-317S.

Marr RA, Hitt M, Muller WJ, Gauldie J, Graham FL.1998. Tumour therapy in mice using adenovirus vectors expressing human $\mathrm{TNF} \alpha$. Int J Oncol 12:509-515.

Mossman KL, Macgregor PF, Rozmus JJ, Goryachev AB, Edwards AM, Smiley JR. 2001. Herpes simplex virus triggers and then disarms a host antiviral response. J Virol 75:750-758.

Mossman KL, Saffran HA, Smiley JR. 2000. Herpes simplex virus ICP0 mutants are hypersensitive to interferon. J Virol 74:2052-2056.

Nicholson KG, Kent J, Hammersley V. 1999. Influenza A among community-dwelling elderly persons in Leicestershire during winter 1993-4: cigarette smoking as a risk factor and the efficacy of influenza vaccination. Epidemiol Infect 123:103-108.

Noyce RS, Collins SE, Mossman KL. 2006. Indentification of a novel pathway essential for the immediate-early, interferon-independent antiviral response to enveloped virions. J Virol 80:226-235.

Paladino P, Cummings DT, Noyce RS, Mossman KL. 2006. The IFNindependent response to virus particle entry provides a first line of antiviral defense that is independent of TLRs and retinoic acid-inducible gene I. J Immunol 177(11):8008-8016.

Panet A. 1983. Regulation of the antiviral and anticellular activities of interferon by exogenous double-stranded RNA. Mol Cell Biochem 52(2):153-160.

Pauwels RA, Buist AS, Calverley PM, Jenkins CR, Hurd SS. 2001. Global strategy for the diagnosis, management, and prevention of chronic obstructive pulmonary disease. NHLBI/WHO Global Initiative for Chronic Obstructive Lung Disease (GOLD) Workshop summary. Am J Respir Crit Care Med 163:1256-1276.

Rahman I, Biswas SK, Kode A. 2006. Oxidant and antioxidant balance in the airways and airway diseases. Eur J Pharmacol 533(1-3):222-239.

Rahman I, MacNee W. 1999. Lung glutathione and oxidative stress: implications in cigarette smoke-induced airway disease. Am J Physiol 277(6 Pt 1):L1067-1088.

Reynolds HY. 2002. Modulating airway defenses against microbes. Curr Opin Pulm Med 8:154-165.

Sato M, Suemori H, Hata N, Asagiri M, Ogasawara K, Nakao K, Nakaya T, Katsuki M, Noguchi S, Tanaka N, Taniguchi T. 2000.
Distinct and essential roles of transcription factors IRF-3 and IRF-7 in response to viruses for IFN-alpha/beta gene induction. Immunity 13:539-548.

Schreiber E HK, Kemler I, Malipiero U, Schaffner W, Fontana A. 1990. Astrocytes and glioblastomoa cells express novel octamer-DNA binding proteins distinct from the ubiquitous Oct-1 and B cell type Oct-2 proteins. Nucleic Acids Res 18(18):5495-5503.

Sen GC. 2001. Viruses and interferons. Annu Rev Microbiol 55:255281.

Servant MJ, Grandvaux N, tenOever BR, Duguay D, Lin R, Hiscott J. 2003. Identification of the minimal phosphoacceptor site required for in vivo activation of interferon regulatory factor 3 in response to virus and double-stranded RNA. J Biol Chem 278:9441-9447.

Sharma S, tenOever BR, Grandvaux N, Zhou GP, Lin R, Hiscott J. 2003. Triggering the interferon antiviral response through the IKKrelated pathway. Science 300:1148-1151.

Sonnenfeld G, Hudgens RW.1986. Effect of sidestream and mainstream smoke exposure on in vitro interferon-alpha/beta production by L929 cells. Cancer Res 46:2779-2783.

Stark GR, Kerr IM, Williams BR, Silverman RH, Schreiber RD. 1998. How cells respond to interferons. Annu Rev Biochem 67:227-264. Stojdl DF, Lichty BD, tenOever BR, Paterson JM, Power AT, Knowles S, Marius R, Reynard J, Poliquin L, Atkins H, Brown EG, Durbin RK, Durbin JE, Hiscott J, Bell JC. 2003. VSV strains with defects in their ability to shut down innate immunity are potent systemic anticancer agents. Cancer Cell 4:263-275.

Tamura S, Kurata T. 2004. Defense mechanisms against influenza virus infection in the respiratory tract mucosa. Jpn J Infect Dis 57:236-247.

Toews G. 1994. Pulmonary clearance of infection. In: JE Pennington, editor. Respiratory infections: Diagnosis and management. 3rd ed. New York: Raven Press, pp. 43-53.

Wathelet MG, Berr PM, Huez GA. 1992. Regulation of gene expression by cytokines and virus in human cells lacking the type-I interferon locus. Eur J Biochem 206:901-910.

Wathelet MG, Lin CH, Parekh BS, Ronco LV, Howley PM, Maniatis T. 1998. Virus infection induces the assembly of coordinately activated transcription factors on the IFN- $\beta$ enhancer in vivo. Mol Cell Biol 1:507-518.

Weaver BK, Kumar KP, Reich NC. 1998. Interferon regulatory factor 3 and CREB-binding protein/p300 are subunits of double stranded RNA-activated transcription factor DRAF1. Mol Cell Biol 18:13591368.

Yoneyama M, Kikuchi M, Natsukawa T, Shinobu N, Imaizumi T, Miyagishi M, Taira K, Akira S, Fujita T. 2004. The RNA helicase RIG-I has an essential function in double-stranded RNA-induced innate antiviral responses. Nat Immunol 5:730-737.

Yoneyama M, Suhara W, Fukuhara Y, Fukuda M, Nishida E, Fujita T. 1998. Direct triggering of the type I interferon system by virus infection: activation of a transcription factor complex containing IRF3 and CBP/p300. EMBO J 17:1087-1095.

Address reprint requests or correspondence to: Dr. Karen L. Mossman Department of Pathology and Molecular Medicine Centre for Gene Therapeutics Michael DeGroote Centre for Learning and Discovery Room 5026

1200 Main Street West Hamilton, Ontario Canada L8N $3 Z 5$

Tel: (905) 525-9140, ext. 23542 Fax: (905) 522-6750

E-mail: mossk@mcmaster.ca

Received 5 June 2007/Accepted 26 September 2007 